\title{
Analisa Faktur Pajak Yang Tidak Dapat Dikreditkan Terhadap Pajak Pertambahan Nilai Terutang (Studi Kasus Pt.Mitra Pemuda Baja Di Tangerang)
}

\author{
Mardiana $^{1}$, Mintauli Debataraja ${ }^{1}$, Meri Mayang Sari ${ }^{3}$ \\ ${ }^{1,2}$ Program Studi Akuntansi Universitas Raharja, ${ }^{3}$ Program Studi Sistem Informasi Universitas \\ Raharja \\ Email: ${ }^{* 1}$ mardiana@ raharja.info, ${ }^{2}$ mintauli@ raharja.info, ${ }^{3}$ meri.mayang@ raharja.info
}

\begin{abstract}
Abstrak
PT. Mitra Pemuda Baja sebagai objek penelitian merupakan perusahaan yang sudah dikukuhkan sebagai Pengusaha Kena Pajak yang bergerak dibidang jasa fabrikasi yang setiap transaksinya mengandung pajak pertambahan nilai yang akan disetor ke kas Negara dengan menggunakan sistem Pajak Masukan dan Pajak keluaran. Pada empat tahun awal pendirian PT. Mitra Pemuda Baja melakukan pembelian beberapa unit mobil serta bangunan dimana faktur pajak masukan yang diterima oleh PT.Mitra Pemuda Baja merupakan faktur pajak yang tidak dapat dikreditkan. Penelitian ini bertujuan untuk mengetahui bagaimana analisa faktur pajak yang tidak dapat dikreditkan terhadap Pajak Pertambahan Nilai Terutang pada PT.Mitra Pemuda Baja. Variabel yang menjadi fokus dari penelitian ini adalah Faktur Pajak Yang Tidak Dapat Dikreditkan sebagai variabel bebas (X), Pajak Pertambahan Nilai Terutang sebagai veriabel terikat (Y). Metode penelitian yang digunakan dalam penelitian ini adalah deskriptif komparatif yaitu pengumpulan data, penjabaran data, dan perbandingan data dilapangan dengan data teori yang ada. Data analisis menggunakan analisis Uji Regresi. Berdasarkan hasil penelitian diketahui bahwa Faktur Pajak Yang Tidak Dapat Dikreditkan memberikan pengaruh yang signifikan terhadap Pajak Pertambahan Nilai Terutang di PT.Mitra Pemuda Baja. Hasil perhitungan dengan menggukan Uji Regresi, menunjukkan nilai $\mathrm{Y}=14.325,5$ dengan meramalkan nilai $\mathrm{X}$ untuk tahun depan sebesar 2.870. Hal ini menunjukkan pengaruh yang signifikan antara faktur pajak yang tidak dapat dikreditkan dengan PPN terutang.
\end{abstract}

\section{Pendahuluan}

Undang-Undang PPN mengatur mengenai saat terutang PPN. Ketentuan ini dipergunakan sebagai dasar untuk menentukan saat pemungutan PPN dan saat pembuatan faktur pajak. Pada prinsipnya PPN terutang bersamaan dengan penyerahan barang atau jasa kena pajak. Dan juga PPN Iterutang terjadi dimasing-masing tempat penyerahan (desentralisasi), kecuali ada ijin sentralisasi (pemusatan) tempat PPN yang terutang.

Perusahaan juga harus menerapkan perhitungan PPN dengan berpedoman pada UndangUndang No.42 Tahun 2009 tentang Pajak Pertambahan Nilai (PPN). Pada PT. Mitra Pemuda Baja, penulis menemukan bahwa mekanisme Pajak Masukan dan Pajak Keluaran belum dilakukan secara benar, dimana pada saat pengkreditan pajak PT.Mitra Pemuda Baja kurang memperhatikan apakah faktur pajak yang diterima dari pelanggan sudah lengkap atau belum dan dari mana faktur pajak masukan tersebut bersumber. Sertanya adanya sejumlah transaksi yang tidak tercatat pada saat pembukuan yang pada dasarnya akan memberikan pengaruh terhadap pajak yang harus disetor ke kas Negara.

Dalam hal ini sesuai dengan penjabaran diatas maka penulis akan mengangkat permasalahan tersebut dalam sebuah penelitian dengan judul: "Analisa Faktur Pajak Yang Tidak Dapat Dikreditkan Terhadap Pajak Pertambahan Nilai (PPN) Terutang pada PT.Mitra Pemuda Baja”. 


\section{Tujuan Penelitian}

Tujuan yang ingin dicapai dari penelitian ini adalah sebagai berikut:

a. Untuk mengetahui apakah semua transaksi di PT Mitra Pemuda Baja sudah menggunakan faktur pajak.

b. Untuk mengetahui perhitungan pajak pertambahan nilai (PPN) terutang pada PT Mitra Pemuda Baja.

c. Untuk mengetahui analisa faktur pajak yang tidak dapat dikreditkan terhadap pajak pertambahan nilai (PPN) terutang pada PT Mitra Pemuda Baja.

\section{Manfaat Penelitian}

Penelitian ini diharapkan memberikan manfaat bagi pihak-pihak yang terkait diantaranya sebagai berikut:

a. Manfaat Praktis

Dapat digunakan sebagai bahan masukan dan pertimbangan dalam mengambil keputusan dan kebijakan dalam perusahaan khususnya PT Mitra Pemuda Baja guna memajukan perusahaan, terkhusus tentang faktur pajak yang tidak dapat dikreditkan terhadap PPN terutang.

b. Manfaat Teoritis

\section{1) Bagi Penulis}

Penelitian ini diharapkan dapat menambah dan memperluas pengetahuan serta pemahaman tentang Pajak Pertambahan Nilai (PPN), khususnya dalam hal faktur pajak yang tidak dapat dikreditkan terhadap PPN terutang.

2) Bagi Akademis Universitas Pamulang

Penelitian ini diharapkan menjadi bahan bacaan dan dapat digunakan sebagai bahan masukan atau media informasi mengenai Pajak Pertambahan Nilai (PPN) dalam hal faktur pajak yang tidak dapat dikreditkan terhadap PPN terutang. Selain itu juga diharapkan sebagai referensi dan pembanding bagi mahasiswa jika dimasa yang akan dating melakukan pengembangan penelitian di bidang yang sama atau melakukan penelitian yang baru yang berkaitan dengan Pajak Pertambahan Nilai (PPN).

3) Bagi Pembaca

Penelitian ini diharapkan dapat menambah pengetahuan dan wawasan pembaca terhadap Pajak Pertambahan Nilai (PPN) khususnya mengenai analisa faktur pajak yang tidak dapat dikreditkan terhadap pajak pertambahan nilai terutang.

\section{Pembatasan Masalah}

Mengingat Pajak Pertambahan Nilai (PPN) merupakan bidang yang sangat kompleks dan luas, dan keterbatasan waktu penelitian dan guna menghindari pembahasan yang tidak terarah, maka penulis membatasi ruang lingkup masalah pada "Analisa Faktur Pajak Yang Tidak Dapat Dikreditkan Terhadap Pajak Pertambahan Nilai (PPN) Terutang pada PT Mitra Pemuda Baja".

\section{Perumusan Masalah}

Berdasarkan dari pembatasan masalah yang telah dikemukakan diatas, maka rumusan masalah yang diajukan dalam penelitian ini adalah:

1. Apakah semua transaksi di PT Mitra Pemuda Baja sudah menggunakan faktur pajak?

2. Bagaimanakah perhitungan pajak pertambahan nilai terutang di PT Mitra Pemuda Baja?

3. Bagaimana analisa faktur pajak yang tidak dapat dikreditkan terhadap pajak pertambahan nilai (PPN) terutang di PT Mitra Pemuda Baja? 


\section{LANDASAN TEORI}

\section{Pengertian Pajak}

Definisi atau pengertian pajak menurut Prof.Dr.Rochmat Soemitro, SH adalah, "Pajak adalah iuran rakyat kepada kas Negara berdasarkan undang-undang (yang dapat dipaksakan) dengan tiada mendapat jasa timbale (kontraprestasi) yang langsung dapat ditunjukkan dan digunakan untuk membayar pengeluaran umum".

\section{Fungsi Pajak}

Adapun fungi pajak menurut Prof.Dr.Rochmat Soemitro,SH ada 2 (dua) yaitu:

a. Fungsi Budgetair

Fungsi Budgetair yaitu Pajak sebagai sumber dana bagi pemerintah untuk membiayai pengeluaran-pengeluarannya.

b. Fungsi Mengatur (reguleerend)

Fungsi mengatur yaitu pajak sebagai alat untuk mengatur atau melaksanaan kebijaksanaan pemerintah dalam bidang social dan ekonomi.

\section{Pengertian Pajak Pertambahan Nilai}

Pajak Pertambahan Nilai adalah pajak atas konsumsi barang dan jasa di Daerah Pabean yang dikenakan secara bertingkat di setiap jalur produksi dan distribusi. (UU No.42 Tahun 2009).

\section{Tarif Pajak Pertambahan Nilai}

Tariff Pajak pertambahan Nilai yang berlaku saat ini adalah 10\% (sepuluh persen). Sedangkan tariff pajak pertambahan nilai sebesar 0\% (nol persen) diterapkan atas:

1) Ekspor Barang Kena Pajak Berwujud

2) Ekspor Barang Kena Pajak Tidak Berwujud

3) Ekspor Jasa Kena Pajak

Pengenaan tariff $0 \%$ (nol persen) tidak berarti pembebasan dari Pengenaan Pajak Pertambahan Nilai. Degan demikian, Pajak Masukan yang telah dibayar untuk memperoleh Barang Kena Pajak/Jasa Kena Pajak yang berkaitan dengan kegiatan tersebut dapat dikreditkan. Berdasarkan pertimbangan ekonomi atau peningkatan kebutuhan dana untuk pembangunan, pemerintah diberi wewenang untuk mengubah tariff Pajak Pertambahan Nilai menjadi paling rendah 5\% (lima persen) dan paling tinggi 15\% (lima belas persen) dengan tetap memakai prinsip tarif tunggal. Perubahan tariff sebagaimana dimaksud pada ayat ini dikemukakan oleh Pemerintah Kepada Dewan Perwakilan Rakyat dalam rangka pembahasan dan penyusutan Rancangan Anggaran Pendapatan dan Belanja Negara.

\section{Objek Pajak Pertambahan Nilai}

Mardiasmo (2011:283) Pajak Pertambahan Nilai dikenakan atas:

a. Penyerahan Barang Kena Pajak (BKP) di dalam Daerah Pabean yang dilakukan oleh Pengusaha.

b. Impor Barang Kena Pajak

c. Penyerahan Jasa Kena Pajak (JKP) di dalam Daerah Pabean yang dilakukan oleh Pengusaha.

d. Pemanfaatan Barang Kena Pajak Tidak Berwujud dari luar Daerah Pabean di dalam Daerah Pabean.

e. Pemanfaatan Jasa Kena Pajak (JKP) dari luar Daerah Pabean di dalam Daerah Pabean,

f. Ekspor Barang Kena Pajak (BKP) Berwujud oleh Pengusaha Kena Pajak,

g. Ekspor Barang Kena Pajak Tidak Berwujud oleh Pengusaha Kena Pajak,

h. Kegiatan membangun sendiri yang dilakukan tidak dalam kegiatan usaha atau pekerjaan oleh orang pribadi atau badan yang hasilnya digunakan sendiri atau digunakan pihak lain, 
i. Penyeraha Barang Kena Pajak berupa aktiva yang menurut tujuan semula tidak untuk diperjualbelikan oleh Pengusaha Kena Pajak, kecuali atas penyerahan aktiva yang Pajak Masukannya tidak dapat dikreditkan.

\section{Dasar Pengenaan Pajak Pertambahan Nilai}

Pasal 1 angka 17 UU PPN menyebutkan Dasar Pengenaan Pajak adalh Harga Jual, Pengganti, Nilai Impor, Nilai Ekspor, atau nilai lain yang dipakai sebagai dasar untuk menghitung pajak yang terutang.

\section{Pengertian Faktur Pajak}

Pasal 1 angka 23 UU PPN menyebutkan Faktur Pajak adalah bukti pungutan pajak yang dibuat oleh Pengusaha Kena Pajak yang melakukan penyerahan Barang Kena Pajak atau penyerahan Jasa Kena Pajak.

Wirawan dan Rudy (2012 : 225) Faktur Pajak merupakan bukti pemungutan PPN atas transaksi impor, penyerahan dalam negeri dan eskpor. Faktur Pajak juga merupakan bukti pengkreditan Pajak Masukan bagi Pengusaha Kena Pajak. Oleh karena itu fungsi Faktur Pajak sangat penting dalam pemungutan, penyetoran dan pelaporan Pajak Pertambahan Nilai.

\section{Pengisian Faktur Pajak}

Faktur Pajak pada prinsipnya harus dibuat lengkap sesuai Pasal 13 ayat 5 UU PPN. Namun sesuai ketentuan Pasal 14 ayat 1 huruf c UU No.6 Tahun 1983 sttdd UU No.28 Tahun 2007 tentang Ketentuan Umum dan Tatacara Perpajakan (UU KUP) Pengusaha Kena Pajak dapat menerbitkan Faktur Pajak tidak lengkap.

Faktur Pajak yang boleh tidak diisi oleh Pengusaha Kena Pajak Penjual adalah:

a. Identitas pembeli, dan

b. Identitas pembeli serta nama dan tandatangan dalam hal penyerahan dilakukan oleh Pengusaha Kena Pajak Pedagang Eceran.

Bagi Pengusaha Kena Pajak Pembeli, Faktur Pajak tersebut harus diisi secara lengkap Pasal 13 ayat 5 UU PPN agar memenuhi syarat formal pengkreditan Pajak Masukan sesuai Pasal 9 ayat 8 huruf f UU PPN. Apabila Faktur Pajak tersebut tidak diisi lengkap menyebabkan Pajak Masukan yang tercantum dalam Faktur Pajak tersebut tidak dapat dikreditkan.

\section{Sanksi Terkait Faktur Pajak}

Sesuai Pasal 14 ayat 1 UU No.6 Tahun 1983 sttdd UU No.28 Tahun 2007 tentang Ketentuan Umum dan Tatacara Perpajakan (UU KUP) yaitu:

1) Pengusaha yang telah dikukuhkan sebagai Pengusaha Kena Pajak, tetapi tidak membuat Faktur Pajak atau membuat Faktur Pajak tapi tidak tepat waktu;

2) Pengusaha yang telah dikukuhkan sebagai Pengusaha Kena Pajak yang tidak mengisi faktur pajak secara lengkap, selain:

a. Identitas pembeli, atau

b. Identitas pembeli serta nama dan tandatangan dalam hal penyerahan dilakukan oleh Pengusaha Kena Pajak Pedagang Eceran.

3) Pengusaha Kena Pajak melaporkan faktur pajak tidak sesuai dengan masa penerbitan Faktur Pajak; atau

Pasal 39A UU No.6 Tahun 1983 sttdd UU No.28 Tahun 2007 tentan Ketentuan Umum dan Tatacara Perpajakan (UU KUP) menyebutkan setiap orang yang dengan sengaja:

1) Menerbitkan dan/atau menggunakan Faktur Pajak, bukti pemungutan pajak, bukti pemotongan pajak, dan/atau bukti setoran pajak yang tidak berdasarkan transaksi yang sebenarnya; atau

2) Menerbitkan faktur pajak tetapi belum dikukuhkan sebagai Pengusaha Kena Pajak Dipidana dengan pidana penjara paling singkat 2 (dua) tahun dan paling lama 6 (enam) 
tahun serta denda paling sedikit 2 (dua) kali jumlah pajak dalam faktur pajak, bukti pemungutan pajak, bukti pemotongan pajak, dan/atau butki setoran pajak dan paling lama 6 (enam) kali jumlah pajak dalam faktur pajak, bukti pemungutan pajak, bukti pemotongan pajak, dan/atau bukti setoran pajak.

\section{Metodologi Penelitian}

\section{Ruang Lingkup Penelitian}

1. Lokasi Penelitian

Penelitian ini di lakukan pada PT.Mitra Pemuda Baja, yang beralamat di Jl.Raya Bantar Gebang - Setu No.8A, Pedurenan, Mustika Jaya - Bekasi.

2. Waktu Penelitian

Penelitian ini dilakukan oleh penulis dari awal bulan Fabruari 2013 sampai awal bulan Maret 2013.

3. Sumber Data

Sumber data yang diambil dari penelitian ini adalah data primer dan data sekunder. Dimana data primer adalah data-data yang diambil langsung dari objek penelitian sedangkan data sekunder adalah data-data yang diambil secara tidak langsung dari objek penelitian.

\section{Metode Penelitian}

Dalam penelitian ini penulis menggunakan metode penelitian deskriptif komparatif yaitu pengambilan data, penjabaran data, dan perbandingan data tentang analisa faktur pajak yang tidak dapat dikreditkan terhadap pajak pertambahan nilai (PPN) terutang di PT.Mitra Pemuda Baja.

\section{Metode Pengumpulan Data}

1. Penelitian Kepustakaan

Penelitian kepustakaan merupakan teknik pengumpulan data yang diambil dari berbagai sumber informasi dengan menggunakan bahan-bahan, mempelajari buku-buku yang berhubungan dengan penelitian ini yang dimaksudkan untuk memperoleh data sekunder.

\section{Penelitian Lapangan}

Penelitian lapangan merupakan teknik pengumpulan data yang diambil langsung dari lapangan dengan cara mempelajari dokumen-dokumen terkait dengan penelitian ini yang dimaksudkan untuk memperoleh data primer di PT.Mitra Pemuda Baja.

\section{Analisis Data}

Dalam penelitian ini penulis mengunakan Metode Analisis Kuantitatif Deskriptif dengan menggunakan uji Regresi yaitu salah satu analisis yang bertujuan untuk mengetahui pengaruh suatu variabel terhadap variabel lainnya. Dimana variabel yang mempengaruhi disebut sebagai variabel independent (variabel bebas) dan variabel yang dipengaruhi disebut sebagai variabel dependent (variabel terikat).

\section{Hasil Dan Pembahasan}

\section{Gambaran Umum PT.Mitra Pemuda Baja}

PT.Mitra Pemuda Baja adalah perusahaan yang didirikan untuk memenuhi kebutuhan dalam tekhnik mesin, seperti jasa permesinan, jasa pembentukan, jasa konstruksi yang memiliki spesialisasi dalam hal roll plate, roll profil (pipa, siku, plat strip, IWF, H-Beam, T-Beam, UNP), Dish End/Bodem, Fabrikasi Tangki. 
PT.Mitra Pemuda Baja didirikan pada bulan Oktober 2009 yang sejak berdiri sampai dengan sekarang terletak di Jalan Raya Bantar Gebang - Setu No.8A Pedurenan, Mustika Jaya Bekasi.

\section{Struktur Organisasi}

Setiap organisasi dalam berbagai bentuk badan hokum memerlukan struktur organisasi guna tercapainya sasaran dan tujuan organisasi. Dimana dalam struktur organisasi tersebut terpampang hubungan antara tiap bagian/deparment dan posisi personil dalam bagiannya untuk menjalin kegiatan operasional. Dan dalam struktur organisasi itu juga ditentukan uraian kerja jabatan, tanggung jawab dan wewenang setiap bagian.

Jika struktur organisasi berjalan dengan baik, tepat dan konsisten dan setiap bagian melakukan pekerjaan atau tugas dengan fungsinya maka akan baik juga organisasi tersebut/perusahaan itu dalam menjalankan usahanya.

\section{Perhitungan Pajak Pertambahan Nilai Terutang}

Sebagai perusahaan yang telah dikukuhkan sebagai Pengusaha Kena Pajak, maka PT.Mitra Pemuda Baja melakukan pengenaan Pajak Pertambahan Nilai dalam penjualan produk berupa Jasa Fabrikasi. Dimana PT Mitra Pemuda Baja melakukan kompensasi apabila dalam suatu masa pajak, Pajak Masukan yang dapat dikreditkan lebih besar dari Pajak Keluaran. Seperti yang telah dibahas pada Bab II bahwa Pajak Keluaran - Pajak Masukan = Pajak yang disetor ke Kas Negara. Sehingga jumlah Pajak Pertambahan Nilai yang disetor tidak selalu sama dengan jumlah Pengenaan Pajak Pertambahan Nilai yang juga diakibatkan oleh adanya Pajak Masukan yang tidak dapat dikreditkan.

Berikut adalah table data jumlah Pajak Pertambahan Nilai Keluaran dan Jumlah Pajak Pertambahan Nilai terutang oleh PT Mitra Pemuda Baja selama 3 (tiga) tahun yaitu dari tahun 2010 sampai 2012 sebagai berikut:

Perhitungan PPN Terutang

\begin{tabular}{|c|c|cc|cc|cr|}
\hline No. & Tahun & \multicolumn{2}{|c|}{ PPN Keluaran } & \multicolumn{2}{c|}{ PPN Masukan } & \multicolumn{2}{c|}{ PPN Terutang } \\
\hline 1 & 2010 & $\mathrm{Rp}$ & 13.066 .657 .340 & $\mathrm{Rp}$ & 6.968 .883 .914 & $\mathrm{Rp}$ & 7.839 .994 .404 \\
\hline 2 & 2011 & $\mathrm{Rp}$ & 15.416 .032 .138 & $\mathrm{Rp}$ & 8.221 .883 .807 & $\mathrm{Rp}$ & 9.249 .619 .283 \\
\hline 3 & 2012 & $\mathrm{Rp}$ & 18.252 .172 .642 & $\mathrm{Rp}$ & 9.734 .492 .076 & $\mathrm{Rp}$ & 10.951 .303 .585 \\
\hline \multicolumn{2}{|c|}{ Total } & $\mathrm{Rp}$ & $\mathbf{4 6 . 7 3 4 . 8 6 2 . 1 2 0}$ & $\mathrm{Rp}$ & $\mathbf{2 4 . 9 2 5 . 2 5 9 . 7 9 7}$ & \multicolumn{2}{|c|}{$\operatorname{Rp} \mathbf{2 8 . 0 4 0 . 9 1 7 . 2 7 2}$} \\
\hline
\end{tabular}

Sumber: PT.Mitra Pemuda Baja dan diolah kembali berikut:

Dari table Pajak Pertambahan Nilai Keluaran dan PPN Terutang dapat diuraikan sebagai

a. Tahun 2010 terdapat PPN Keluaran sebesar Rp 13.066.657.340,- dan PPN Terutang sebesar Rp 7.839.994.404,- ini dikarenakan adanya Pajak Pertambahan Nilai Masukan yang tidak dapat dikreditkan sebesar Rp 1.742.220.979,- yaitu Pajak Masukan atau Faktur Pajak yang berasal dari luar usaha PT.Mitra Pemuda Baja yakni pada bulan Maret 2010 PT.Mitra Pemuda Baja melakukan pembelian mobil dan truk yang digunakan sebagai mobil operasional.

b. Tahun 2011 terdapat PPN Keluaran sebesar Rp 15.416.032.138,- dan PPN Terutang sebesar Rp 9.249.619.283,- yang dikarenakan adanya Faktur Pajak yang tidak dapat dikreditkan sebesar Rp 2.055.470.925,- yang diakibatkan oleh adanya Faktur Pajak cacat juga adanya Faktur Pajak yang bersumber dari transaksi diluar bidang usaha PT Mitra Pemuda Baja serta adanya transaksi pembelian satu buah rumah yang diperuntukkan sebagai mes bagi karyawan PT.Mitra Pemuda Baja.

c. Tahun 2012 terdapat PPN Keluaran sebesar Rp 18.252.172.642,- dan PPN Terutang sebesar Rp 10.951.303.585,- hal ini dikarenakan oleh adanya Faktur Pajak cacat, Faktur 
Pajak tidak lengkap dan Faktur Pajak yang bersumber dari luar bidang usaha salah satunya yaitu adanya pembelian bangunan sebagai penambahan workshop baru.

\section{Laporan Transaksi Dengan Faktur Pajak}

Berikut adalah laporan transaksi dengan faktur pajak di PT Mitra Pemuda Baja selama 3 (tiga) tahun berturut-turut yaitu Tahun 2010, 2011 dan 2012 dan juga Laporan Pajak Pertambahan Nilai Terutang, yaitu sebagai berikut:

a. Transaksi Dengan Faktur Pajak pada Tahun 2010

Adapun data transaksi dengan menggunakan faktur pajak pada PT.Mitra Pemuda Baja pada Tahun 2010 adalah sebagai berikut:

Transaksi dengan Faktur Pajak Pada Tahun 2010

\begin{tabular}{|c|c|cr|rr|ll|}
\hline No. & Bulan & \multicolumn{2}{|c|}{ DPP } & \multicolumn{2}{c|}{ PPN KELUARAN } & \multicolumn{2}{c|}{ PPN MASUKAN } \\
\hline 1 & Januari & $\mathrm{Rp}$ & 7.940 .127 .523 & $\mathrm{Rp}$ & 794.012 .752 & $\mathrm{Rp}$ & 423.473 .468 \\
\hline 2 & Februari & $\mathrm{Rp}$ & 7.502 .713 .914 & $\mathrm{Rp}$ & 750.271 .391 & $\mathrm{Rp}$ & 400.144 .742 \\
\hline 3 & Maret & $\mathrm{Rp}$ & 10.556 .416 .255 & $\mathrm{Rp}$ & 1.055 .641 .626 & $\mathrm{Rp}$ & 563.008 .867 \\
\hline 4 & April & $\mathrm{Rp}$ & 9.002 .857 .089 & $\mathrm{Rp}$ & 900.285 .709 & $\mathrm{Rp}$ & 480.152 .378 \\
\hline 5 & Mei & $\mathrm{Rp}$ & 10.422 .440 .322 & $\mathrm{Rp}$ & 1.042 .244 .032 & $\mathrm{Rp}$ & 555.863 .484 \\
\hline 6 & Juni & $\mathrm{Rp}$ & 10.476 .149 .432 & $\mathrm{Rp}$ & 1.047 .614 .943 & $\mathrm{Rp}$ & 558.727 .970 \\
\hline 7 & Juli & $\mathrm{Rp}$ & 10.968 .949 .507 & $\mathrm{Rp}$ & 1.096 .894 .951 & $\mathrm{Rp}$ & 585.010 .640 \\
\hline 8 & Agustus & $\mathrm{Rp}$ & 11.788 .263 .353 & $\mathrm{Rp}$ & 1.178 .826 .335 & $\mathrm{Rp}$ & 628.707 .379 \\
\hline 9 & September & $\mathrm{Rp}$ & 11.076 .894 .181 & $\mathrm{Rp}$ & 1.107 .689 .418 & $\mathrm{Rp}$ & 590.767 .690 \\
\hline 10 & Oktober & $\mathrm{Rp}$ & 12.809 .712 .032 & $\mathrm{Rp}$ & 1.280 .971 .203 & $\mathrm{Rp}$ & 683.184 .642 \\
\hline 11 & Nopember & $\mathrm{Rp}$ & 14.706 .835 .434 & $\mathrm{Rp}$ & 1.470 .683 .543 & $\mathrm{Rp}$ & 784.364 .556 \\
\hline 12 & Desember & $\mathrm{Rp}$ & 13.415 .214 .355 & $\mathrm{Rp}$ & 1.341 .521 .436 & $\mathrm{Rp}$ & 715.478 .099 \\
\hline & Total & $\mathrm{Rp}$ & $\mathbf{1 3 0 . 6 6 6 . 5 7 3 . 3 9 7}$ & $\mathrm{Rp}$ & $\mathbf{1 3 . 0 6 6 . 6 5 7 . 3 4 0}$ & $\mathrm{Rp}$ & $\mathbf{6 . 9 6 8 . 8 8 3 . 9 1 4}$ \\
\hline
\end{tabular}

Sumber :PT.Mitra Pemuda Baja dan diolah kembali

b. Transaksi Dengan Faktur Pajak pada Tahun 2011

Berikut disajikan data transaksi dengan faktur pajak pada PT. Mitra Pemuda Baja selama Tahun 2011, sebagai berikut:

\section{Transaksi Dengan Faktur Pajak Pada 2011}

\begin{tabular}{|c|c|c|c|c|c|c|c|}
\hline No. & Bulan & \multicolumn{2}{|r|}{ DPP } & \multicolumn{2}{|c|}{ PPN KELUARAN } & \multicolumn{2}{|c|}{ PPN MASUKAN } \\
\hline 1 & Januari & $\mathrm{Rp}$ & 10.313 .460 .073 & $\mathrm{Rp}$ & 1.031 .346 .007 & $\mathrm{Rp}$ & 550.051 .204 \\
\hline 2 & Februari & $\mathrm{Rp}$ & 11.797 .855 .584 & $\mathrm{Rp}$ & 1.179 .785 .558 & $\mathrm{Rp}$ & 629.218 .964 \\
\hline 3 & Maret & $\mathrm{Rp}$ & 11.775 .675 .221 & $\mathrm{Rp}$ & 1.177 .567 .522 & $\mathrm{Rp}$ & 628.036 .012 \\
\hline 4 & April & $\mathrm{Rp}$ & 12.691 .043 .832 & $\mathrm{Rp}$ & 1.269.104.383 & $\mathrm{Rp}$ & 676.855 .671 \\
\hline 5 & Mei & $\mathrm{Rp}$ & 12.755 .134 .819 & $\mathrm{Rp}$ & 1.275 .513 .482 & $\mathrm{Rp}$ & 680.273 .857 \\
\hline 6 & Juni & $\mathrm{Rp}$ & 11.984 .847 .771 & $\mathrm{Rp}$ & 1.198 .484 .777 & $\mathrm{Rp}$ & 639.191 .881 \\
\hline 7 & Juli & $\mathrm{Rp}$ & 14.394 .120 .745 & $\mathrm{Rp}$ & 1.439 .412 .075 & $\mathrm{Rp}$ & 767.686 .440 \\
\hline 8 & Agustus & $\mathrm{Rp}$ & 12.905 .422 .190 & $\mathrm{Rp}$ & 1.290 .542 .219 & $\mathrm{Rp}$ & 688.289 .183 \\
\hline 9 & September & $\mathrm{Rp}$ & 12.667 .132 .412 & $\mathrm{Rp}$ & 1.266 .713 .241 & $\mathrm{Rp}$ & 675.580 .395 \\
\hline 10 & Oktober & $\mathrm{Rp}$ & 13.951 .324 .715 & $\mathrm{Rp}$ & 1.395 .132 .471 & $\mathrm{Rp}$ & 744.070 .651 \\
\hline 11 & Nopember & $\mathrm{Rp}$ & 11.993 .025 .807 & $\mathrm{Rp}$ & 1.199 .302 .581 & $\mathrm{Rp}$ & 639.628 .043 \\
\hline 12 & Desember & & 16.931 .278 .215 & $\mathrm{Rp}$ & 1.693 .127 .822 & $\mathrm{Rp}$ & 903.001 .505 \\
\hline & Total & $\mathbf{R p}$ & 154.160.321.384 & & 5.416.032.138 & & 221.883.807 \\
\hline
\end{tabular}


c. Transaksi Dengan Faktur Pajak pada Tahun 2012

Berikut disajikan data transaksi dengan faktur pajak pada PT.Mitra Pemuda Baja selama Tahun 2012, sebagai berikut:

Transaksi Dengan Faktur Pajak Pada Tahun 2012

\begin{tabular}{|c|c|cc|lr|rr|}
\hline No. & Bulan & \multicolumn{2}{|c|}{ DPP } & \multicolumn{2}{c|}{ PPN KELUARAN } & \multicolumn{2}{c|}{ PPN MASUKAN } \\
\hline 1 & Januari & $\mathrm{Rp}$ & 11.164 .839 .935 & $\mathrm{Rp}$ & 1.116 .483 .994 & $\mathrm{Rp}$ & 595.458 .130 \\
\hline 2 & Februari & $\mathrm{Rp}$ & 13.531 .345 .319 & $\mathrm{Rp}$ & 1.353 .134 .532 & $\mathrm{Rp}$ & 721.671 .750 \\
\hline 3 & Maret & $\mathrm{Rp}$ & 11.477 .294 .917 & $\mathrm{Rp}$ & 1.147 .729 .492 & $\mathrm{Rp}$ & 612.122 .396 \\
\hline 4 & April & $\mathrm{Rp}$ & 14.701 .400 .318 & $\mathrm{Rp}$ & 1.470 .140 .032 & $\mathrm{Rp}$ & 784.074 .684 \\
\hline 5 & Mei & $\mathrm{Rp}$ & 12.910 .531 .863 & $\mathrm{Rp}$ & 1.291 .053 .186 & $\mathrm{Rp}$ & 688.561 .699 \\
\hline 6 & Juni & $\mathrm{Rp}$ & 14.189 .599 .397 & $\mathrm{Rp}$ & 1.418 .959 .940 & $\mathrm{Rp}$ & 756.778 .635 \\
\hline 7 & Juli & $\mathrm{Rp}$ & 17.610 .921 .135 & $\mathrm{Rp}$ & 1.761 .092 .113 & $\mathrm{Rp}$ & 939.249 .127 \\
\hline 8 & Agustus & $\mathrm{Rp}$ & 15.956 .152 .523 & $\mathrm{Rp}$ & 1.595 .615 .252 & $\mathrm{Rp}$ & 850.994 .801 \\
\hline 9 & September & $\mathrm{Rp}$ & 15.170 .181 .021 & $\mathrm{Rp}$ & 1.517 .018 .102 & $\mathrm{Rp}$ & 809.076 .321 \\
\hline 10 & Oktober & $\mathrm{Rp}$ & 14.178 .467 .583 & $\mathrm{Rp}$ & 1.417 .846 .758 & $\mathrm{Rp}$ & 756.184 .938 \\
\hline 11 & Nopember & $\mathrm{Rp}$ & 18.455 .437 .354 & $\mathrm{Rp}$ & 1.845 .543 .735 & $\mathrm{Rp}$ & 984.289 .992 \\
\hline 12 & Desember & $\mathrm{Rp}$ & 23.175 .555 .055 & $\mathrm{Rp}$ & 2.317 .555 .505 & $\mathrm{Rp}$ & 1.236 .029 .603 \\
\hline & Total & $\mathrm{Rp}$ & $\mathbf{1 8 2 . 5 2 1 . 7 2 6 . 4 1 9}$ & $\mathrm{Rp} \mathbf{1 8 . 2 5 2 . 1 7 2 . 6 4 2}$ & $\mathrm{Rp} \mathbf{9 . 7 3 4 . 4 9 2 . 0 7 6}$ \\
\hline
\end{tabular}

Sumber: PT.Mitra Pemuda Baja dan diolah kembali

\section{Perkembangan Pengenaan Pajak Pertambahan Nilai}

Dari Tabel 4.1 PPN Keluaran dan PPN Terutang dapat dilihat bahwa jumlah PPN Terutang selalu mengalami peningkatan setiap tahunnya. Hal ini diakibatkan karena adanya peningkatan penjualan berupa jasa dari tahun ke tahun. Menurut informasi yang penulis peroleh dari sumber yaitu PT.Mitra Pemuda Baja peningkatan penjualan yang dialami oleh PT.Mitra Pemuda Baja karena adanya perkembangan pembangunan baik pembangunan gedung-gedung ataupun pembangunan jalan raya seperti misalnya jembatan laying jalan tol. Berikut ini adalah perkembangan pengenaan pajak pertambahan nilai di PT.Mitra Pemuda Baja selama 3 (tiga) tahun berturut-turut yaitu mulai Tahun 2010-2012 sebagai berikut:

Perkembangan Pengenaan PPN

\begin{tabular}{|c|c|c|c|c|c|c|c|}
\hline \multirow{2}{*}{ No. } & \multirow{2}{*}{ Tahun } & \multirow{2}{*}{ DPP } & \multirow{2}{*}{\multicolumn{2}{|c|}{ PPN }} & \multicolumn{3}{|c|}{$\begin{array}{c}\text { Besarnya Kenaikan \& } \\
\text { Penurunan }\end{array}$} \\
\hline & & & & & & (Rupiah) & $(\%)$ \\
\hline 1 & 2010 & Rp 130.666.573.397 & $\mathrm{Rp}$ & 13.066 .657 .340 & $\mathrm{Rp}$ & - & - \\
\hline 2 & 2011 & Rp 154.160 .321 .384 & $\mathrm{Rp}$ & 15.416 .032 .138 & $\mathrm{Rp}$ & 2.349 .374 .799 & 18 \\
\hline 3 & 2012 & Rp 182.521.726.419 & $\mathrm{Rp}$ & 18.252.172.642 & $\mathrm{Rp}$ & 2.836 .140 .503 & 18 \\
\hline \multicolumn{2}{|c|}{ Total } & Rp 467.348.621.200 & $\mathbf{R p}$ & 46.734.862.120 & $\mathbf{R p}$ & 5.185.515.302 & \\
\hline
\end{tabular}

Sumber: PT.Mitra Pemuda Baja dan diolah kembali

Dari tabel di atas dapat diuraikan sebagai berikut:

a. Tahun 2011 dibandingkan dengan Tahun 2010 terjadikan kenaikan pengenaan Pajak Pertambahan Nilai, dimana total PPN pada Tahun 2010 adalah sebesar Rp 13.066.657.340,- (tiga belas milyar enam puluh enam juta enam ratus lima puluh tujuh ribu tiga ratus empat puluh rupiah) sedangkan total PPN pada Tahun 2011 sebesar Rp 15.416.032.138,- (lima belas milyar empat ratus enam belas juta tiga puluh dua ribu seratus 
tiga puluh delapan rupiah) atau setara dengan persentasi kenaikan sebesar $18 \%$ (delapan belas persen).

b. Tahun 2012 dibandingkan dengan Tahun 2012 juga terjadi kenaikan PPN, dimana total PPN pada Tahun 2011 adalah sebesar Rp 15.416.032.138,- (lima belas milyar empat ratus enam belas juta tiga puluh dua ribu seratus tiga puluh delapan rupiah) sedangkan pada Tahun 2012 total PPN sebesar Rp 18.252.172.642,- (delapan belas milyar dua ratus lima puluh dua juta seratus tujuh puluh dua ribu enam ratus empat puluh dua rupiah) atau setara juga dengan persentasi kenaikan sebasar 18\% (delapan belas persen).

\section{Laporan PPN Terutang}

Adanya perkembangan dalam pengenaan Pajak Pertambahan Nilai akan berpengaruh pada besarnya Pajak Pertambahan Nilai Terutang pada akhir Tahun Pajak. Berikut adalah data tabel PPN Terutang pada PT.Mitra Pemuda Baja, sebagai berikut:

\section{Laporan PPN Terutang}

\begin{tabular}{|c|c|cc|cc|}
\hline \multirow{2}{*}{ NO. } & \multirow{2}{*}{ Tahun } & \multicolumn{2}{|c|}{$\begin{array}{c}\text { PPN Yang Tdk Dpt } \\
\text { Dikreditkan }(\mathbf{X})\end{array}$} & \multicolumn{2}{c|}{ PPN Terutang (Y) } \\
\hline 1 & 2010 & $\mathrm{Rp}$ & 1.742 .220 .979 & $\mathrm{Rp}$ & 7.839 .994 .404 \\
\hline 2 & 2011 & $\mathrm{Rp}$ & 2.055 .470 .952 & $\mathrm{Rp}$ & 9.249 .619 .283 \\
\hline 3 & 2012 & $\mathrm{Rp}$ & 2.433 .623 .019 & $\mathrm{Rp}$ & 10.951 .303 .585 \\
\hline \multicolumn{2}{|c|}{ Total } & $\mathrm{Rp}$ & $\mathbf{6 . 2 3 1 . 3 1 4 . 9 4 9}$ & $\mathrm{Rp}$ & $\mathbf{2 8 . 0 4 0 . 9 1 7 . 2 7 2}$ \\
\hline
\end{tabular}

Sumber: PT.Mitra Pemuda Baja dan diolah kembali

Dari tabel di atas dapat diuraikan sebagai berikut:

a. Pada Tahun 2010 terdapat Pajak Pertambahan Nilai Yang Tidak Dapat Dikreditkan sebesar Rp 1.742.220.979,- (satu milyar tujuh ratus empat puluh dua juta dua ratus dua puluh ribu sembilan ratus tujuh puluh sembilan rupiah) dan Pajak Pertambahan Nilai Terutang sebesar Rp 7.839.994.404,- (tujuh milyar delapan ratus tiga puluh sembilan juta sebilan ratus sembilan puluh empat ribu empat ratus empat rupiah).

b. Pada Tahun 2011 terdapat Pajak Pertambahan Nilai Yang Tidak Dapat Dikreditkan sebesar Rp 2.055.470.952,- (dua milyar lima puluh lima juta empat ratus tujuh puluh ribu sembilan ratus lima puluh dua rupiah) dan Pajak Pertambahan Nilai Terutang sebesar Rp 9.249.619.283,- (sembilan milyar dua ratus empat puluh sembilan juta enam ratus sembilan belas ribu dua ratus depalan puluh tiga rupiah).

c. Pada Tahun 2012 terdapat Pajak Pertambahan Nilai Yang Tidak Dapat Dikreditkan sebesar Rp 2.433.623.019,- (dua milyar empar ratus tiga puluh tiga juta enam ratus dua puluh tiga ribu sembilan belas rupiah) dan Pajak Pertambahan Nilai Terutang sebesar Rp 10.951.303.585,- (sepuluh milyar sembilan ratus lima puluh satu juta tiga ratus tiga ribu lima ratus delapan puluh lima rupiah).

\section{Analisa Faktur Pajak Yang Tidak Dapat Dikreditkan Terhadap Pajak Pertambahan Nilai Terutang}

Untuk menganalisa Faktur Pajak Pertambahan Nilai Yang Tidak Dapat Dikreditkan Terhadap Pajak Pertambahan Nilai Terutang dapat dianalisa dengan menggunakan metode analisa statistic, yaitu analisa regresi. Adapun perhitungannya sebagai berikut: 
Analisa Regresi antara Faktur Pajak Yang Tidak Dapat Dikreditkan terhadap Pajak Pertambahan Nilai Terutang PT.Mitra Pemuda Baja Tahun 2010-2012

(Dalam Jutaan Rupiah)

\begin{tabular}{|c|c|c|c|c|c|c|}
\hline No. & Tahun & $\begin{array}{c}\text { FP Yang Tdk } \\
\text { Dpt } \\
\text { Dikreditkan } \\
(\mathbf{X})\end{array}$ & $\begin{array}{c}\text { PPN } \\
\text { Terutang } \\
(\mathbf{Y})\end{array}$ & $\mathbf{X . Y}$ & $\mathbf{X}^{\mathbf{2}}$ & $\mathbf{Y}^{\mathbf{2}}$ \\
\hline 1 & 2010 & 1.742 & 7.839 & 13.655 .538 & 3.034 .564 & 61.449 .921 \\
\hline 2 & 2011 & 2.055 & 9.249 & 19.006 .695 & 4.223 .025 & 85.544 .001 \\
\hline 3 & 2012 & 2.433 & 10.951 & 26.643 .783 & 5.919 .489 & 119.924 .401 \\
\hline \multicolumn{2}{|c|}{ Total } & $\mathbf{6 . 2 3 0}$ & $\mathbf{2 8 . 0 3 9}$ & $\mathbf{5 9 . 3 0 6 . 0 1 6}$ & $\mathbf{1 3 . 1 7 7 . 0 7 8}$ & $\mathbf{2 6 6 . 9 1 8 . 3 2 3}$ \\
\hline
\end{tabular}

Diketahui:
$\mathrm{N} \quad=3$
$\sum X \quad=6.230$
$\sum \mathrm{Y}=28.039$
$\sum X Y=59.306 .016$
$\sum X^{2}=13.177 .078$
$\sum \mathrm{Y}^{2}=266.918 .323$

Dengan meramalkan nilai (x) untuk tahun depan:

$1.433 \times 18 \%=437$

$\mathrm{x}=2.433+437$

$\mathrm{x}=2.870$

jadi nilai (x) untuk tahun depan yaitu Tahun $2013 \mathrm{x}=2.870$

$\mathrm{Y}=\mathrm{a}+\mathrm{bx}$

$\mathrm{a}=\frac{\left(\sum Y\right) \cdot\left(\sum X^{2}\right)-\left(\sum X\right) \cdot\left(\sum X Y\right)}{n \sum X^{2}-\left(\sum X\right)^{2}}$

$\mathrm{a}=\frac{(28.038) \cdot(13.177 .078)-(6.230) \cdot(59.306 .016)}{3(13.177 .078)-(6.230)^{2}}$

$\mathrm{a}=\frac{369.458 .912 .964-369.076 .079 .680}{3(13.177 .078)-38.812 .900}$

$\mathrm{a}=\frac{-17.566 .716}{39.531 .234-38.812 .900}$

$\mathrm{a}=\frac{-17.566 .716}{718.334}$

$a=-24,4548$

$\mathrm{b}=\frac{n \sum X Y-\left(\sum X\right) \cdot\left(\sum Y\right)}{n \sum X^{2}-\left(\sum X\right)^{2}}$

$\mathrm{b}=\frac{3(59.306 .016)-(6.230) \cdot(28.038)}{3(13.177 .078)-(6.230)^{2}}$

$\mathrm{b}=\frac{177.918 .048-174.682 .970}{39.531 .234-38.812 .900}$

$\mathrm{b}=\frac{3.235 .078}{718.334}$

$\mathrm{b}=5$

maka nilai (Y) adalah:

$\mathrm{Y}=\mathrm{a}+\mathrm{bx}$

$\mathrm{Y}=-24,4548+5(2.870)$

$\mathrm{Y}=-24,4548+14.350$

$\mathrm{Y}=14.325,5$ 
Dari perhitungan analisa Regresi diatas, maka dapat dibuat sebuah analisa mengenai Faktur Pajak Yang Tidak Dapat Dikreditkan Terhadap Pajak Pertambahan Nilai Terutang sebagai berikut:

a. Dengan meramalkan jumlah nilai faktur pajak yang tidak dapat dikreditkan untuk tahun 2013 yaitu senilai Rp 2.870,- (dalam jutaan rupiah) maka jumlah PPN Terutangnya menjadi senilai Rp 14.325,5 (dalam jutaan rupiah).

b. Jika semua Pajak Masukan tersebut bisa dikreditkan maka akan mengurangi jumlah PPN Terutang menjadi Rp 14.325,5 - Rp 2.870 = Rp 11.455,5 (semua dalam jutaan rupiah).

c. Dari hasil analisa diatas bisa kita lihat bahwa Faktur Pajak Yang Tidak Dapat Dikreditkan memberikan pengaruh terhadap Pajak Pertambahan Nilai Terutang.

\section{Kesimpulan}

Berdasarkan penelitian dan pembahasan yang penulis lakukan mengenai Analisa Faktur Pajak Yang Tidak Dapat Dikreditkan Terhadap Pajak Pertambahan Nilai Terutang, maka dapat ditarik kesimpulan sebagai berikut:

1. Berdasarkan data Tabel 4.2 Transaksi Dengan Menggunakan Faktur Pajak serta hasil penelitian yang dilakukan oleh penulis, maka dapat disimpulkan bahwa sebagian besar transaksi yang terjadi di PT.Mitra Pemuda Baja sudah menggunakan Faktur Pajak atau sudah dikenakan Pajak Pertambahan Nilai (PPN) sebesar 10\% (sepuluh persen).

2. Berdasarkan dari data Tabel 4.1 Perhitungan PPN Terutang, maka penulis dapat simpulkan bahwa perhitungan PPN Terutang yang terjadi di PT.Mitra Pemuda Baja adalah dengan mengurangi Pajak Keluaran dengan Pajak Masukan yang dapat dikreditkan serta yang tidak dapat dikreditkan barulah bisa diketahui berapa besar PPN Terutang dalam satu tahun pajak. Di Tahun 2010 terdapat PPN Terutang sebesar Rp7.839.994.404,- tahun 2011 sebesar Rp 9.249.619.404,- dan Tahun 2012 sebesar Rp 10.951.303.585,-. PPN Terutang yang dimaksud disini adalah PPN Terutang sebelum dikurangi dengan PPN Lebih Bayar pada Tahun sebelumnya.

3. Berdasarkan perhitungan analisa regresi terbukti bahwa Faktur Pajak Yang Tidak Dapat Dikreditkan memberikan pengaruh yang signifikan terhadap Pajak Pertambahan Nilai Terutang. Dengan Meramalkan nilai (X) sebesar 2.870 (dalam jutaan rupiah) yang diperoleh berdasarkan kenaikan 18\% (delapan belas persen) maka terdapat Pajak Pertambahan Nilai Terutang sebesar 14.325,5 (dalam jutaan rupiah). Maka penulis dapat simpulkan Faktur Pajak Yang Tidak Dapat Dikreditkan meningkat, maka Pajak Pertambahan Nilai Terutang akan menurun. Itulah sebabnya kenapa dalam analisa regresi menunjukkan bahwa variabel bebas (X) yaitu Faktur Pajak Yang Tidak Dapat Dikreditkan memberikan pengaruh yang kuat terhadap variabel terikat $(\mathrm{Y})$ yaitu Pajak Pertambahan Nilai Terutang.

\section{Saran}

Dari hasil penelitian dan pembahasan yang dilakukan penulis yang telah ditarik kesimpulan, maka penulis memberikan saran sebagai berikut :

1. Dalam hal menerima Faktur Pajak Masukan sebaiknya PT.Mitra Pemuda Baja benar-benar melakukan pengecekan yang mendetail apakah Faktur Pajak Masukan itu bisa dijadikan sebagai kredit pajak atau tidak, karena hal ini akan sangat mempengaruhi besar kecilnya Pajak Terutang yang harus disetor oleh PT.Mitra Pemuda Baja ke Kas Negara.

2. Sebagai Perusahaan yang telah dikukuhkan sebagai Pengusaha Kena Pajak (PKP) maka sudah sepatutnya PT.Mitra Pemuda Baja menerapkan perhitungan Pajak Pertambahan Nilai (PPN) dengan berpedoman pada Undang-Undang PPN No.42 tahun 2009. 
Daftar Pustaka

[1] Anastasia Diana, "Perpajakan Indonesia", Andi, Yogyakarta, 2009.

[2] Asrofi, Zaenal, "Pengaruh Pengenaan Pajak Pertambahan Nilai Terhadap Hasil Penjualan”, Skripsi Tahun 2012 Universitas Pamulang, Tangerang, 2012.

[3] B.Ilyas, Wirawan dan Rudi Suhartono, "PERPAJAKAN: Pembahasan Lengkap Berdasarkan Perundang-Undangan dan Aturan Pelaksanaan Terbaru", Mitra Wacana Media, Jakarta, 2012.

[4] Budi Waluyo, Didik, "Pajak Pertamabahan Nilai Barang dan Jasa dan Pajak Penjualan Atas Barang Mewah", PT Gramedia, Jakarta, 2010.

[5] Diaz, Priantara, "Perpajakan Indonesia", Edisi 2, Mitra Wacana Medika, Jakarta, 2012.

[6] Dwikora, Harjo, "Perpajakan Indonesia”, Mitra Wacana Media, Jakarta, 2013.

[7] Erly, Suandy, "Perpajakan”, Edisi 2, Salemba Empat, Jakarta, 2007.

[8] Judisseno, Rimsky D.2004. Perpajakan: Edisi Revisi.Jakarta: Gramedia Pustaka Utama

[9] M. Burhan, Bungin, "Metodologi Penelitian Kuantitatif”, Kencana Predana Media Group, Jakarta, 2009.

[10] Mardiasmo, “Perpajakan”, Edisi Revisi Tahun 2009, Andi, Yogyakarta, 2009.

[11] Mardiasmo, "Perpajakan”, CV Andi Offet, Yogyakarta, 2011.

[12] Muslim, “Metode Penelitian”, Seri Diklat Kuliah, Universitas Pamulang, 2011.

[13] Prastowo, Yustinus, "Panduan Lengkap PAJAK", Raih Asa Sukses, Depok, 2010. Resmi, Siti. 2011. Perpajakan: Teori dan Kasus Edisi 6. Jakarta: Salemba Empat

[14] Rohmat Amin,dkk, "Pajak Terapan Brevet A dan B Terpadu", Penerbit Bina Fiskal Indonesia, Tangerang, 2011.

[15] Rochmat, Sumitro, “Perpajakan”, Edisi Revisi, Salemba Empat, Jakarta, 2006.

[16] Ronny, Kountur, "Metode Penelitan untuk Penyusunan Skripsi dan Tesis", PPM, Jakarta, 2007.

[17] Rudy, Suhartono, “Ensiklopedia Perpajakan”, Salemba Empat, Jakarta, 2010.

[18] Thomas, Sumarsan, "Perpajakan Indonesia”, Edisi 2, Indeks, Jakarta, 2012.

[19] Sudirman,\&,Amiruddin. 2012. Perpajakan: Pendekatan Teori dan Praktik. Malang: Empat Dua Media

[20] Sugiyono, "Metode Penelitian Kuantitatif Kualitatif dan R\&D”,Alfabeta, Bandung, 2011.

[21] Sukardji, Untung, "Pajak Pertambahan Nilai", PT Multi Utama Consultindo, Jakarta, 2010. 
[22] Undang - Undang Nomor 42 Tahun 2009 tentang Pajak Pertambahan Nilai Barang dan Jasa Dan Pajak Penjualan Atas Barang Mewah.

[23] Undang - Undang Nomor 28 Tahun 2007 tentang Ketentuan Umum Dan Tatacara Perpajakan.

[24] Undang - Undang Pajak Lengkap Tahun 2010, Mitra Wacana Media, Jakarta, 2010. Waluyo, "Akuntansi Pajak", Salemba Empat, Jakarta, 2004.

[25] Waluyo, "Perpajakan Indonesia", Edisi Delapan, Buku Kesatu, Salemba Empat, Jakarta, 2008.

[26] Wirawan, B. Hyas, "Perpajakan”, Mitra Wacana Media, Jakarta, 2012. 